\title{
EDUCAÇÃO DOS SURDOS NO BRASIL: UM PERCURSO HISTÓRICO E NOVAS PERSPECTIVAS
}

\author{
EDUCATION OF THE DEAF IN BRAZIL: \\ A HISTORICAL OVERVIEW AND NEW PERSPECTIVES \\ LA EDUCACIÓN DE LOS SORDOS EN BRASIL: \\ UN RECORRIDO HISTÓRICO Y NUEVAS PERSPECTIVAS
}

\author{
Quintino Martins de Oliveira* \\ Francisco José Quaresma Figueiredo **
}

\section{Resumo}

Este artigo discute algumas questões teóricas de bilinguismo (BAKER, 2004; GROSJEAN, 1982; MYERS-SCOTTON, 2006), tendo como foco a educação de surdos no Brasil (FELIPE, 2006; FERNANDES, 1990; LACERDA e LODI, 2009; QUADROS, 2012) e suas implicações na constituição do sujeito surdo. As reflexões sobre as questões linguísticas dentro do espaço escolar têm mostrado uma tendência bilíngue para a educação de surdos. Esse método pedagógico considera a língua brasileira de sinais (libras) como língua de instrução, e o ensino da língua portuguesa, como segunda língua, na modalidade escrita. Os estudos revisados neste artigo revelam que é necessária uma reflexão sobre o processo de inclusão dos alunos surdos na escola e que esta não pode ser ancorada simplesmente na inserção desses alunos com os alunos ouvintes em salas regulares, conforme presenciamos hoje nas escolas públicas (FELIPE, 2006). São necessárias mudanças na estrutura escolar, no que diz respeito à validação dos direitos linguísticos dos surdos, uma vez que as relações didático-pedagógicas consideram as peculiaridades das diferentes modalidades de ambas as línguas, bem como a relação entre língua, cultura, identidade do surdo e interação, fatores fundamentais em seu desenvolvimento escolar e social.

Palavras-chave: Educação de surdos, Interação, Processo de aprendizagem.

\footnotetext{
* Mestre em Letras e Linguística pela UFG. Professor de Libras na UFT e tradutor -intérprete de língua brasileira de sinais/português, e-mail: qmoliveira.neto@gmail.com

** Doutor e Pós-Doutor em Linguística Aplicada pela UFMG. Professor Titular de Língua Inglesa da Faculdade de Letras da UFG, e-mail: fquaresma@terra.com.br
} 


\section{Introdução}

Neste artigo, trazemos uma revisão da literatura sobre as abordagens de ensino desenvolvidas na educação do povo surdo ${ }^{1}$. Apresentamos o oralismo, que visa à promoção da fala oral, bem como à proibição do uso de sinais dentro das escolas. Discorremos, também, sobre a comunicação total, que visa ao uso simultâneo das duas línguas. Outra abordagem apresentada é a educação inclusiva, que se propõe a resolver o atraso no desenvolvimento de linguagem, socializando surdos e ouvintes numa mesma proposta educacional. Por fim, tratamos da educação bilíngue para surdos, que propõe o uso da libras ${ }^{2}$ como língua de instrução no contexto escolar e a aprendizagem da língua portuguesa como segunda língua, na modalidade escrita, bem como discutimos sobre a importância da interação no processo de aprendizagem dos surdos.

\section{Oralismo}

$\mathrm{Na}$ constituição social do surdo, há uma forte presença da visão do ouvinte que resultou em leituras marcadas por muitos estereótipos, pois foram construídos através da imposição da sociedade dominante, traçados por representações sociais que ditam o povo surdo como seres deficientes. Lane (1995) apresenta essa leitura equivocada, enfatizada na fala do ex-presidente da World Federation of the Deaf ${ }^{3}$ (WTD), o sociólogo surdo Dr. Yerker Anderson, que afirma ser lamentável "o conhecimento limitado sobre os surdos que os autores ouvintes possuem quando escrevem acerca da questão da surdez” (LANE, 1995, p. 13).

O resgate histórico educacional situa os surdos em um contexto marcado fortemente por considerações distorcidas acerca de sua incapacidade de ouvir, oriunda, a princípio, das relações médicas, enxergando-os como alguém que tem uma patologia que necessita ser corrigida e consertada. Tais considerações têm como parâmetro de normalização a sociedade ouvinte, que busca “ouvintizar" os surdos (SOUZA, 1998, p. 4). É salutar ressaltar que essa visão não era comungada por todos da área da saúde. O médico neurologista Oliver Sacks (1998, p. 15), por exemplo, ao afirmar que "somos notavelmente ignorantes a respeito da surdez” (SACKS, 1998, p. 15), nos esclarece, em seus estudos, que os surdos não apresentam impedimentos cognitivos por não desenvolverem a língua oral. Segundo o autor, os surdos possuem língua e cultura que são manifestadas diferentemente das dos ouvintes, contrariando muitos estudiosos de sua área. 
Em relação à educação do sujeito surdo, podemos observar constantes discussões tendo como foco questões linguísticas (LACERDA; LODI, 2009). As propostas educacionais voltadas para esse público vêm sendo, ao longo dos tempos, direcionadas ao desenvolvimento da língua utilizada pelos ouvintes, no nosso caso, a língua portuguesa de forma oral. Conforme afirma Goldfeld (1997, p. 12), o avanço das tecnologias desenvolvidas para esse fim $^{4}$ atraiu alguns educadores, que passaram a considerar que a aquisição da língua de sinais dificultaria a aprendizagem da língua oral pelo surdo.

A partir dessa postura, os estudos voltados à educação de surdos focaram-se no desenvolvimento da fala e da audição por uma série de técnicas terapêuticas que ocuparam os espaços educacionais, transformando as salas de aula em verdadeiros consultórios fonoaudiológicos. Assim, eram realizadas com os sujeitos surdos terapias intensivas de fala e de leitura labial ${ }^{5}$, acreditando-se ser esse o caminho ideal para o desenvolvimento de sua linguagem. Essa abordagem de ensino ficou conhecida como oralismo (CAPOVILLA, 2000; GOLDFELD, 1997; LACERDA, 1998).

Segundo Goldfeld (1997, p. 35), além do fato de a língua oral não poder ser adquirida naturalmente pelo surdo, visto que ele "não tem o principal sensor necessário à aquisição desse tipo de língua", o oralismo mostrou, ao longo dos anos, uma série de limitações no desenvolvimento da aprendizagem da língua oral nos surdos. Tal abordagem desconsiderava as línguas de sinais como línguas naturais de comunicação e expressão do sujeito surdo, bem como sua identificação com essa língua na construção de sua identidade linguística e sociocultural.

As propostas do oralismo persistiram e foram marcantes nas décadas de 1960, mas até os dias atuais, não conseguiram promover a aquisição da língua oral pelo surdo espontaneamente. As dificuldades de aprendizagem da língua oral tornaram as relações sociais dos surdos com a comunidade ouvinte desafiadoras, pois essa proposta não proporcionava interações comunicativas fluidas. A visão equivocada dos profissionais que atuavam com surdos acerca da língua de sinais, não a considerando como uma língua natural nas interações dentro da escola, resultou em altos números de desistência escolar por parte dos surdos.

Posteriormente, uma nova abordagem veio a integrar a realidade educacional dos surdos. Passou-se a considerar a língua de sinais como auxiliar na aquisição da língua oral para os alunos surdos (CICCONE, 1990; QUADROS, 1997; RABELO, 1992a, 1992b; 
SACKS, 1998). Essa abordagem ficou conhecida como comunicação total, a qual passamos a descrever na próxima seção.

\section{Comunicação total}

A comunicação total foi uma nova abordagem que aliava diferentes metodologias e estratégias para o ensino da língua oral aos surdos. Nela, a interação social comunicativa do indivíduo surdo pautava-se na prática de técnicas que desenvolviam sua fala oralizada, pois, apenas com o uso de sinais, o surdo não conseguiria interagir plenamente com o meio social (CICCONE, 1990). Dessa maneira, passou-se a considerar, no desenvolvimento da comunicação total: a língua oral, a de sinais, a datilologia ${ }^{6}$, a combinação dessas três formas de comunicação e ainda outros meios, como o uso de técnicas e recursos voltados para a estimulação auditiva, adaptação de aparelho de amplificação sonora individual, leitura labial e oralização.

Segundo Rabelo (1992a, 1992b), na perspectiva da comunicação total o surdo teria seu desenvolvimento cognitivo assegurado por meio de uma prática composta de linguagem sinalizada, acrescida de gestos e de sinais ancorados na estrutura sintática da língua portuguesa. Essa estratégia ficou conhecida como português sinalizado ${ }^{7}$. Para Rabelo (1992a, 1992b), somente com o uso dos sinais, o surdo ficaria prejudicado no desenvolvimento das três funções básicas da língua oral, sobre as quais dissertamos a seguir:

a) Como fator de interação social: Rabelo (1992a, 1992b) chama-nos a refletir sobre o contexto no qual os surdos são filhos de pais ouvintes. Na relação entre pais ouvintes com seus filhos surdos, a autora nos orienta que não há uma possibilidade dos pais em se posicionarem enquanto surdos, nem de fazer seus bebês se comportarem como ouvintes, sendo, portanto, a comunicação total a posição intermediária que poderia viabilizar essa interação.

b) Como fator de transmissão cultural: a autora apresenta alguns exemplos do cotidiano de uma criança surda a qual está inserida no contexto majoritariamente ouvinte. A preocupação de Rabelo (1992a, 1992b) evidencia-se quando ela afirma que o contexto é nossa maior fonte de transmissão cultural. Como os surdos não têm a possibilidade de ter o domínio da língua oral exposta nos diferentes meios comunicativos, acabam ficando marginalizados e, com isso, torna-se difícil a eles assimilar a única cultura reconhecida e validada socialmente, ou seja, a cultura 
ouvinte, a qual, no Brasil, é compartilhada por meio da língua portuguesa. Nessa perspectiva, a única forma de acesso à cultura seria por meio do português sinalizado.

c) Como instrumento para a elaboração do raciocínio formal e abstrato: em seus estudos, Rabelo (1992a, 1992b) afirma que, se o surdo não for exposto o suficiente a um ambiente linguístico, seu cérebro não será capaz de desenvolver as conexões cognitivas necessárias para a construção do pensamento abstrato e simbólico. Para a autora, isso afetaria o estabelecimento de uma linguagem e o desenvolvimento do surdo ficaria restrito a etapas do raciocínio concreto, e esse cenário só poderia ser modificado com a aprendizagem da língua portuguesa, pois somente assim ele conseguiria ampliar sua interação social e alcançar a etapa do pensamento formal e abstrato e apossar-se da cultura a que ele tem direito, atual e acessível a ele através do uso do português sinalizado.

O português sinalizado caracteriza-se pelo uso do alfabeto manual, também chamado de alfabeto dactilológico, que propõe marcas aditivas à linguagem sinalizada nativa, formando uma gramática o mais próxima possível à do português. Conforme aponta Rabelo (1992a, p. 15), o português sinalizado estabelecia-se, entre outras regras, da seguinte maneira:

\footnotetext{
a ordem das palavras nas frases mantém a mesma estrutura das do Português; os artigos e preposições inexistentes são feitos em alfabeto dactilológico; o feminino dos pronomes (meu-minha), dos indefinidos (um-uma-algum-alguma), dos adjetivos (bonito-bonita) é marcado com o acréscimo da letra e ao gesto inicial; o plural na linguagem nativa é feito com o sinal ${ }^{8}$ de "muitos". Substituímos esta forma de plural com o acréscimo da letra $s$ ao gesto inicial.
}

Nessa abordagem, houve, no Brasil, inúmeras tentativas no uso de ambas as línguas no processo de ensino-aprendizagem dos surdos. A libras era adequada à estrutura sintática do português, como suporte para o ensino dessa língua oral como a única língua favorável nas escolas (CUMMINS, 2009). Assim, para os estudiosos da comunicação total, a única forma de assegurar uma interação comunicativa eficaz capaz de promover o desenvolvimento da linguagem nos surdos era por meio de estratégias que levassem ao uso simultâneo da oralização e do português sinalizado, processo esse definido como bimodalismo (CICCONE, 1990; GOLDFELD, 1997; RABELO, 1992a, 1992b). O uso da língua de sinais era aceito como um recurso no processo de ensino da língua oral (CICCONE, 1990; GOLDFELD, 
1997; RABELO, 1992a, 1992b). No entanto, a comunicação total continuava a desconsiderar os aspectos linguísticos naturais da língua de sinais e a estruturava com base nas relações gramaticais das línguas orais; ou seja, os profissionais da educação de surdos, à época, utilizavam o léxico da língua de sinais submetido à gramática da língua oral (GOLDFELD, 1997). Conforme nos esclarece Goldfeld (1997), de acordo com os pressupostos dessa abordagem, ocorreram diversas tentativas de aproximação das duas línguas, o que ocasionou a criação de línguas orais sinalizadas.

Apesar de o uso da língua de sinais ter sido contemplado, mesmo precariamente, na comunicação total implementada nos espaços escolares, a educação dos surdos continuou resultando em fracassos. Começaram, então, a surgir novos estudos que apresentaram evidências para validar as línguas de sinais como línguas naturais (FERREIRA, 2010; FOX, 2007; KLIMA; BELLUGI, 1980; LACERDA, 1998; QUADROS, 1997; SANDLER; LILLOMARTIN, 2006; VALLI et al., 2011) e a preocupação em integrar os sujeitos surdos na sociedade.

Diversos estudiosos de diferentes áreas começaram a voltar seus olhares à integração dos surdos, já não mais vistos como deficientes, mas como pessoas que têm uma língua diferente da língua majoritária, no nosso caso, da língua portuguesa. Assim, por meio da Lei de Diretrizes e Bases da Educação (BRASIL, 1996), foi assegurado aos surdos o ensino especial em escolas regulares no país, garantindo-lhes o direito de conviver com a diferença e, por meio dela, de se desenvolverem na interação com os alunos ouvintes. A escola passou a ser entendida como um espaço de consenso e de tolerância para com os diferentes (MACHADO, 2006), surgindo, desse modo, a Educação Inclusiva, abordagem atual no sistema educacional do Brasil, como veremos a seguir.

\section{Educação inclusiva}

As políticas de valorização ${ }^{9}$ das diferenças e da aceitabilidade dos deficientes nos espaços públicos educacionais passaram a garantir a integração das pessoas com deficiência na sociedade, rompendo com as antigas políticas que se caracterizavam como segregadoras, por manterem os deficientes isolados da sociedade. A partir dos anos 1990, foi implementada a abordagem educacional inclusiva, tendo como pressuposto a inclusão de alunos com deficiências nas escolas regulares, que passaram a ser chamadas de escolas inclusivas. Nessa proposta, há uma preocupação em integrar os deficientes aos ambientes comuns das escolas 
regulares, acreditando-se que, ao se colocar um indivíduo com necessidade educacional especial no sistema regular de educação, o processo de interação promoveria resultados positivos no desenvolvimento psicossocial, cognitivo, afetivo e cultural dos então chamados "portadores de necessidades especiais".

A Federação Nacional de Integração dos Surdos (FENEIS) ${ }^{10}$ iniciou seu movimento político nos anos 1990, em busca da conquista da oficialização da libras, do reconhecimento do profissional instrutor surdo e do intérprete educacional de libras ${ }^{11}$, na tentativa de promover mudanças na política inclusiva para atender às demandas educativas da comunidade surda nos espaços educacionais (FELIPE, 1997, 2006).

Em Goiás, nesse mesmo período, os surdos foram transferidos para escolas estaduais, que passaram a oferecer a modalidade de ensino especial. No entanto, diversos entraves no processo de aprendizagem dos alunos, nessas escolas, começaram a ser evidenciados e, devido às movimentações da comunidade surda, na busca de melhorias nesse processo, começaram a ser propostos diferentes projetos de Lei para a oficialização da libras como língua natural dos surdos. A mais recente e relevante conquista da comunidade surda foi a aprovação da Lei $n^{\circ}$ 9.681, de 23 de outubro de 2015, que determina e regulamenta a criação da escola bilíngue para surdos. Apesar de essa lei ter sido aprovada na câmara de vereadores de Goiânia, ela ainda não foi implementada, o que tem prejudicado a qualidade da educação de surdos nessa cidade.

Perlin (1998) e Quadros $(1997,2012)$ apontam as condições desiguais oferecidas aos alunos surdos no processo de aprendizagem, quando comparadas àquelas ofertadas aos alunos ouvintes, afirmando que não são contempladas as necessidades dos surdos nesse processo educacional. Para as autoras, os conhecimentos são viabilizados unicamente na língua portuguesa e, por isso, não alcançam os surdos. Devido às dificuldades dos alunos surdos com essa língua, acabam sendo prejudicados quanto à quantidade e à qualidade das informações que poderiam receber, caso as recebessem em língua de sinais (MACHADO, 2006).

Para Marchesi e Martín (1995), nas escolas regulares inclusivas não há o reconhecimento da diferença cultural ${ }^{12}$ dos surdos. Não há espaços para manifestações culturais em suas formas particulares de expressão, pois, nesse modelo educacional, os surdos são colocados em programas elaborados por ouvintes e voltados para ouvintes, sem a participação de surdos. Devido ao fato de sua língua e sua cultura não serem privilegiadas nesse contexto, os surdos acabam não se identificando como sujeitos participantes das 
atividades de sua escola, restringindo-se unicamente a copiar as atividades em sala (MACHADO, 2006).

No que concerne às práticas pedagógicas, voltadas à educação de surdos na perspectiva inclusiva, muitas inquietações surgiram diante do cenário de fracassos escolares percebidos nesse contexto educacional, como o fraco domínio da leitura e da escrita na língua portuguesa (LACERDA, 1998). Além disso, são também evidenciados problemas referentes a questões linguísticas e psicossociais dos surdos, visto que a sua língua é usada unicamente na mediação estabelecida pelo intérprete educacional de libras.

Nesse contexto de escola inclusiva, também podemos observar que aspectos referentes às peculiaridades da aquisição da língua de sinais são ignorados. Nessas escolas, não é ofertado o ensino de libras para os surdos como primeira língua, prejudicando as interações entre sujeitos surdos, fundamentais para as construções de cultura e identidade surdas (FERNANDES, 1990; FERREIRA-BRITO, 1990; GÓES, 1999; QUADROS, 1997; SKLIAR, 2015; SOUZA, 1998).

Os autores que pesquisam as abordagens de ensino aplicadas aos alunos surdos nas escolas inclusivas afirmam que estes ficam prejudicados, quando comparados àquelas ofertadas aos alunos ouvintes. Embora haja intérpretes de libras para mediar a comunicação, esses profissionais não conseguem atender às demandas linguísticas e nem tradutórias necessárias ao desenvolvimento educacional dos alunos surdos, pois não cabe exclusivamente aos intérpretes mediar o processo de aprendizagem desses alunos. Os ouvintes estão naturalmente emergidos em um contexto linguístico que os favorece, por se comunicarem e se expressarem por meio da língua oral. Segundo Chaveiro (2011) e Oliveira-Silva (2017), esse cenário acaba prejudicando os surdos, por se encontrarem, muitas vezes, ilhados nesse universo oral-auditivo e impedidos de interagir com outros colegas surdos em sua língua natural, pois, geralmente, há um aluno surdo por sala. Além disso, devido à dificuldade que esses alunos têm em relação às línguas orais, acabam sendo prejudicados quanto à quantidade e à qualidade das informações que poderiam acessar, caso isso se desse em língua de sinais (MACHADO, 2006; PERLIN, 2012; QUADROS, 1997).

São inúmeros os relatos de pessoas surdas e de pesquisadores da área que demonstram os prejuízos causados aos surdos, especialmente quanto aos seus processos cognitivos, devido a abordagens educacionais que não contemplavam as especificidades linguísticas, culturais e sociais dos surdos, como, por exemplo, o oralismo, a comunicação total e a educação 
inclusiva (ALBRES, 2010; FERNANDES, 1990; GÓES, 1999; GOLDFELD, 1997; LEMOS, 2002). Tais abordagens tornam limitado o processo de aprendizagem dos alunos surdos, pois não levavam em consideração as especificidades tanto do indivíduo surdo, pertencente a um grupo linguístico minoritário ${ }^{13}$ (SANTOS, 2016; STROBEL, 2009), quanto da forma como as línguas de sinais são estruturadas e produzidas (ANATER, 2009; ARROTÉIA, 2005; FELIPE; MONTEIRO, 2008; PICONI, 2014; QUADROS; KARNOPP, 2004).

Estudos voltados para sujeitos bilíngues ${ }^{14}$, cujas línguas são de modalidades diferentes, vêm contribuindo e norteando reflexões sobre esse tipo de produção linguística. Conforme mostram algumas pesquisas, sujeitos bilíngues, cujas línguas envolvidas são orais, não conseguem produzir as duas línguas simultaneamente, por terem apenas um único processo de output ${ }^{15}$ disponível. Assim, mesmo em um ambiente bilíngue, cujas línguas são de modalidades diferentes, também não é possível a produção simultânea de ambas as línguas (EMMOREY et al., 2008; MEIER, 2002), o que refuta o mito de que tal produção simultânea das duas línguas seja naturalmente possível, como era preconizado por autores da comunicação total (CICCONE, 1990; RABELO, 1992a, 1992b).

Conforme afirma Oliveira-Silva (2017), tanto a língua de sinais quanto a língua oral são relevantes para a comunidade surda, pois ocupam diferentes posições em suas vidas. Segundo a autora, a língua de sinais permeia toda a construção de linguagem e de identidade nos surdos. Por sua vez, a língua oral tem um papel fundamental na interação comunicativa com as pessoas que não sabem a língua de sinais.

Partindo dos estudos linguísticos e culturais dos surdos, uma nova proposta educacional começa a surgir para atender às demandas sociais da comunidade surda, que contempla a língua de sinais como língua de instrução e o ensino da língua portuguesa como segunda língua, na modalidade escrita. Essa abordagem é conhecida como Educação Bilíngue para Surdos, a qual passamos a discutir na próxima seção.

\section{Educação bilíngue para surdos}

A escola inclusiva, como vimos, é caracterizada por políticas monolíngues que privilegiam unicamente a língua e os processos culturais do ouvinte. Tais políticas, dessa forma, desrespeitam a Lei $n^{\circ} 10.436 / 2002$ (BRASIL, 2002) e o Decreto $n^{\circ} 5.626 / 2005$ (BRASIL, 2005), que asseguram ao surdo o direito de ter uma educação bilíngue em libras e em português. 
Para Grosjean (1982), as políticas linguísticas públicas de um país sempre favorecem uma língua em detrimento de outras. Embora a Lei $n^{\circ}$ 10.436/2002 (BRASIL, 2002) reconheça a libras como língua de expressão e de comunicação da comunidade surda, ao pensar na educação do sujeito surdo, ainda se está longe da efetivação desse processo, visto que a primazia é do ensino da língua portuguesa.

$\mathrm{Na}$ tentativa de buscar atender às especificidades dos alunos surdos e superar antigos entraves nessa relação, um novo olhar sobre sua formação e sobre seu direito a uma experiência bilíngue começa a surgir (LACERDA; LODI, 2009). A educação bilíngue para surdos enfatiza a relevância de a criança surda ser exposta, o mais precocemente possível, à língua de sinais, no intuito de desenvolver suas capacidades e competências linguísticas no percurso natural, da mesma maneira como ocorre com as crianças ouvintes.

No Brasil, estudos sobre bilinguismo para surdos começaram a surgir no campo da linguística, trazendo para o foco das pesquisas diversos temas relacionados à libras, à cultura surda e à identidade surda (FERREIRA-BRITO, 1993; PERLIN, 1998; PIRES; LOPES, 2007; QUADROS, 1997; SKLIAR, 2015). Tais estudos ajudaram a construir um novo pensar pedagógico do sujeito surdo, partindo do pressuposto de que ele possui identidade e cultura específicas de sua comunidade, cuja língua é de "modalidade vísuo-espacial" (QUADROS; KARNOPP, 2004). Ajudaram também a ver o surdo não mais como um sujeito que necessita ter sua surdez "consertada" para adquirir uma língua natural, mas como um sujeito que possui língua, identidade e cultura diferentes.

A abordagem educacional bilíngue para surdos parte do pressuposto de que a criança surda deva ser exposta à língua de sinais por meio de interações com professores adultos surdos, que sejam participantes e atuantes da comunidade surda (LACERDA; LODI, 2009; QUADROS, 2012; SKLIAR, 2015). Por meio dessa interação, é possível a construção da cultura e da identidade surda.

No contexto de uma educação bilíngue para surdos, entende-se um movimento político linguístico de "adição" de línguas e não de "subtração" de uma em detrimento de outras (CUMMINS, 2009) e, conforme aponta Baker (2011), os surdos se tornam bilíngues aprendendo, primeiramente, a língua de sinais e, posteriormente, a segunda língua na modalidade escrita. Baker (2011) chama a atenção para especificidades do bilinguismo dos surdos, ressaltando que há características que lhes são peculiares. Quadros (2012), ao falar sobre bilinguismo dos surdos brasileiros, elenca algumas, a saber: a) a modalidade das 
línguas: vísuo-espacial e oral-auditiva; b) surdos filhos de pais ouvintes: os pais não conhecem a língua de sinais brasileira; c) o contexto de aquisição da língua de sinais: um contexto atípico, uma vez que a língua é adquirida tardiamente, mas mesmo assim tem status de L1; e d) a idealização institucional do status bilíngue para os surdos: as políticas públicas determinam que os surdos "devem" aprender português.

Portanto, uma escola que atenda às diversas especificidades dos surdos precisa ser pensada a partir da relação desses sujeitos com o seu desenvolvimento de linguagem, pois devemos nos ater às contribuições de sua primeira língua na aprendizagem da segunda língua. Conforme explica Mello (2004, 2010), o ensino de L2 pode beneficiar-se do uso da L1 e as funções que cada uma terá dependerão de seu contexto de uso (BAKER, 2004, 2011). Assim, a educação bilíngue para surdos parte da compreensão de uma educação de assimilação, não só linguística, mas também cultural, pois entendemos que o ensino bilíngue não se atém unicamente a questões linguísticas (MELLO, 2010), mas contempla também questões de ordem política, social e cultural. Ao pensar em sujeitos surdos bilíngues, partimos dos estudos de Baker (2004, p. 9) que entende o bilíngue como sujeito que "usa suas duas línguas com pessoas diferentes, em diferentes contextos para propósitos diferentes"16. O nível de proficiência em uma língua dependerá de cada contexto.

Por essas e outras razões, o bilinguismo deve ser considerado como o uso que as pessoas fazem de duas línguas diferentes em diferentes contextos sociais (QUADROS, 2012). Nessa direção, a língua portuguesa, para os surdos, terá uma função social diferente da que tem para os ouvintes, e o modo como ela será ensinada também deverá respeitar as características culturais do sujeito surdo. Portanto, uma proposta educacional bilíngue para surdos deve romper com os pressupostos das abordagens anteriores e considerar as especificidades visuais dos surdos contempladas no processo de ensino da língua oral, na modalidade escrita, bem como nas metodologias utilizadas no ensino das disciplinas que compõem o currículo escolar, que devem ser ensinadas na língua de sinais.

A predominância da língua portuguesa nas escolas inclusivas tem afetado a autoestima dos alunos surdos, levando-os a se sentirem inseguros e desconfortáveis para expressar suas ideias e construir suas identidades por meio da libras. Outra maneira de olhar para esse espaço conflituoso e amenizar as tensões seria promover momentos e situações de alternância entre as línguas (MELLO, 2008), nos quais pudessem ser contempladas as trocas socioculturais 
entre os alunos surdos e ouvintes, propiciando, assim, um ambiente mais favorável à aprendizagem.

É salutar ressaltar que o ensino de uma segunda língua, no caso, o português na modalidade escrita, pode ser beneficiado com o ensino da escrita na primeira língua. Portanto, embora a Lei $n^{\circ} 10.436 / 2002$ e o Decreto $n^{\circ} 5.626 / 2005$ determinem que o ensino de português deva ser promovido na modalidade escrita, o educador poderá favorecer o processo de aprendizagem do aluno surdo com o ensino da escrita de sua primeira língua, promovendo, assim, o empoderamento da comunidade surda, ao viabilizar uma forma de expressão na escrita de sua própria língua natural (BARROS, 2015).

Para Stumpf (2015, p. 11), “não há escrita oficial para a língua de sinais”, e as políticas públicas atuais não delegam a obrigatoriedade de seu ensino, como o faz com a escrita da língua portuguesa. No Brasil, temos, atualmente, dois sistemas de escrita de língua de sinais mais conhecidos: a Escrita das Línguas de Sinais - EliS e o SignWriting. A ELiS é um sistema brasileiro criado pela professora e pesquisadora da Universidade Federal de Goiás, Mariângela Estelita Barros, ao passo que o SignWriting é um sistema criado nos Estados Unidos por Valérie Sutton. Os dois sistemas vêm sendo testados na pesquisa e na produção de materiais didáticos voltados ao ensino de libras para surdos e ouvintes, bem como ao ensino de português para os surdos.

Os dois sistemas se estruturam a partir dos parâmetros fonológicos das línguas sinalizadas. Como são sistemas que ainda estão sendo difundidos na comunidade surda brasileira, alguns irão preferir um sistema a outro (BARROS, 2015; STUMPF; QUADROS, 2010; WANDERLEY, 2015).

Devemos levar em consideração que, quando um indivíduo aprende uma segunda língua, na modalidade escrita, esse processo pode ser favorecido pelas experiências que ele teve ao escrever em sua primeira língua (FIGUEIREDO, 2015). Esse favorecimento nem sempre é vivenciado pelos surdos, visto que a escrita da língua de sinais ainda não é difundida em contextos escolares, ocorrendo o seu uso, principalmente, nos cursos de graduação em Letras: Libras e em pesquisas cientificas (BARROS, 2015; PEREIRA, 2014). Assim, a difusão da escrita de língua de sinais em contextos escolares poderá favorecer a aprendizagem da língua portuguesa, na modalidade escrita, pelos surdos (LACERDA; LODI, 2009; PEREIRA, 2009). Ao dominar a escrita, o surdo poderá se comunicar de forma eficaz e fluida com as pessoas com as quais interage. 
Para promover mais situações de interação entre surdos e ouvintes, a escola poderia desenvolver sessões bilíngues que propiciassem um contexto colaborativo de aprendizagem de libras como língua adicional ${ }^{17}$ para ouvintes e de português como segunda língua para surdos. Acreditamos que propostas pedagógicas que contemplem a alternância na aprendizagem de ambas as línguas podem favorecer reflexões não só quanto ao ensino das línguas envolvidas, mas também sobre a visão que um tem do outro, com suas percepções culturais e comportamentais. Ao promover um contexto colaborativo, a escola poderá se tornar um ambiente mais coeso quanto a questões sociais e linguísticas dos surdos.

No contexto de aprendizagem de línguas dos surdos, saber a relevância que a língua de sinais e a língua oral têm para eles contribui para a compreensão de seu processo de aprendizagem. Como elucida Oliveira-Silva (2017, p. 22), reconhecer a relevância que ambas as línguas têm para o desenvolvimento dos surdos "é o passo inicial para a proposição de abordagens adequadas de ensino". A interação entre pessoas surdas e ouvintes com diferentes níveis de habilidades - bem como sua percepção do outro (surdo ou ouvinte) no processo de aprendizagem de línguas orais e sinalizadas - pode apontar estratégias diferentes, que venham oportunizar a aprendizagem em contextos colaborativos. Conforme aponta Vygotsky (1998), a interação entre duas ou mais pessoas com competências linguísticas diferentes pode otimizar trocas significativas que favoreçam o processo de ensino-aprendizagem das línguas envolvidas.

\section{A importância da interação no processo de aprendizagem}

Vygotsky (2008) reconhece a língua de sinais como uma língua que pode promover interação comunicativa significativa para o processo de aprendizagem dos surdos. Conhecer essa língua implica compreender o seu sistema de recepção e produção, que se estabelece diferentemente das línguas orais. Segundo Figueiredo e Oliveira-Silva (2016) e Oliveira-Silva (2017), para que o processo de ensino-aprendizagem se estabeleça é fundamental que o professor do aluno surdo seja proficiente em língua de sinais. Caso contrário, não conseguirá mediar o processo de construção de conhecimentos.

Para Souza e Almeida (2014), a interação entre os indivíduos viabiliza novas experiências e vivências que promovem novos conhecimentos. Eles afirmam que a comunicação promovida por meio da interação entre esses sujeitos é um pressuposto fundamental para aprender a língua do outro. Segundo esses autores, aprender a língua de 
sinais vai além da busca equivalente de significados entre sinais e palavras. Aprender uma nova língua é compartilhar novos saberes sobre as coisas do mundo. Por meio da interação entre surdos e ouvintes, novos conhecimentos linguísticos e culturais podem ser adquiridos (DOMAGALA-ZYSK, 2013; SOUZA; ALMEIDA, 2014).

As pesquisas sobre a interação promovida em salas de aula de L2 têm demonstrado a dinamicidade do processo de ensino-aprendizagem, distanciando-se da crença de um ensino estático e fragmentado (FIGUEIREDO, 2006a). Para compreendermos melhor esses estudos, os quais embasam esta pesquisa, passamos a discorrer sobre a teoria sociocultural de Vygotsky e a aprendizagem colaborativa.

A aprendizagem colaborativa de línguas refere-se a situações de aprendizagem em contextos educativos em que duas ou mais pessoas trabalham, por meio de diferentes estratégias interacionais, mediadas por objetos ou por outras pessoas, para executar alguma ação ou tarefa, levando-os a colaborar uns com os outros na coconstrução de algum conhecimento (DONATO, 1994; FIGUEIREDO, 2006b, 2015; FIGUEIREDO; SILVA, 2014; FIGUEREDO，2001; OLIVEIRA-SILVA，2017; RIGONATO，2017; SABOTA，2006; VYGOTSKY, 1998).

A abordagem colaborativa de línguas traz em seus pressupostos teóricos a teoria sociocultural de Vygotsky (1998). Para esse autor, o desenvolvimento cognitivo do indivíduo vincula-se ao contexto social, histórico e cultural, compreendendo, assim, esse desenvolvimento, levando-se em conta duas dimensões: o social e o individual. Segundo o autor, a aprendizagem está associada às experiências promovidas no meio social, mediadas na interação e dirigidas para o individual.

Assim, todos os processos desenvolvidos socialmente são depois reconstruídos internamente, ou seja, tornam-se internalizados (VYGOTSKY, 1998). Assim, o professor de línguas deve considerar todas as interações que possuam significado no processo de aprendizagem de línguas. Deve também levar em conta que as experiências vividas em sala de aula vão além do momento da aula. Segundo Figueiredo (2006b, p. 12), “o homem é um ser social e aprende por meio da interação com outras pessoas", e essa interação é fundamental para o desenvolvimento cognitivo dos indivíduos.

Apesar de as línguas de sinais e as línguas orais não compartilharem a mesma modalidade linguística, uma sendo vísuo-espacial e a outra oral-auditiva, surdos e ouvintes, numa interação colaborativa de línguas, podem utilizar de diferentes estratégias de apoio na 
mediação da aprendizagem da língua um do outro (FIGUEIREDO; SILVA, 2014; OLIVEIRA; FIGUEIREDO, 2017). Os scaffoldings ${ }^{18}$, compartilhados através da interação linguística entre eles, possibilitam-lhes não só obter conhecimento linguístico, mas também conhecimento cultural na língua do outro. Assim, uma abordagem colaborativa de aprendizagem de línguas oferece aos aprendizes oportunidades tanto de input quanto de output.

Segundo Oliveira (1998, p. 24), “a relação do homem com o mundo não é uma relação direta, mas uma relação mediada, sendo os sistemas simbólicos os elementos intermediários entre o sujeito e o mundo". Em outras palavras, o desenvolvimento sociocognitivo do indivíduo se estabelece por meio de interações produzidas com o uso de instrumentos, como o uso de materiais, ou por meio de um sistema de símbolos, como a linguagem.

Tomando-se por base a teoria sociocultural, podemos perceber que a importância do papel da interação em sala de aula é algo indiscutível, pois “o conhecimento é coconstruído e a aprendizagem sempre envolve mais do que uma pessoa" (NYIKOS; HASHIMOTO, 1997, p. 507). Na sala de aula de línguas, seja de L1 ou de L2, a interação ainda é mais importante, pois a língua é tanto o objeto de conhecimento quanto o meio para a aprendizagem (TSUI, 1995).

\section{Considerações finais}

A história de educação dos surdos sempre foi pautada nos modelos ouvintes existentes e acreditava-se ser esse o caminho libertador para o seu desenvolvimento educacional. Por muito tempo, o surdo foi visto como um sujeito deficiente e incapaz, que precisava ser curado por meio da oralização (BAKER, 2004). As políticas públicas inclusivas, preocupadas em restabelecer esse sujeito e integrá-lo na sociedade, prejudicaram seu processo de aprendizagem, por não considerarem os fatores necessários para uma reorganização da estrutura que atendesse às necessidades pedagógicas e linguísticas dos surdos. Esse fato resultou em um alto índice de desistência e constante sentimento de fracasso desses alunos no aprendizado da língua portuguesa, bem como dos conteúdos do currículo escolar. Nesse cenário, muitas das vezes a responsabilidade docente vem sendo passada para o intérprete de libras educacional, que não tem a função de docente entre as suas atribuições.

Por meio dos estudos aqui apresentados, concluímos que as propostas de uma educação bilíngue parecem ser as mais compatíveis com as especificidades dos surdos, por estabelecerem uma integração da libras e do português em seu processo de aprendizagem. A 
interação em sala de aula, deve ser estimulada, de modo que surdos, ouvintes, intérpretes educacionais e o professor possam participar da construção de conhecimentos e de trocas significativas de auxílios e saberes, tornando-se, portanto, coautores de um processo educacional do qual todos possam participar.

\begin{abstract}
This article discusses some theoretical questions concerning bilingualism (BAKER, 2004; GROSJEAN, 1982; MYERS-SCOTTON, 2006) and focuses on the education of the deaf in Brazil (FELIPE, 2006; FERNANDES, 1990; LACERDA \& LODI, 2009; QUADROS, 2012) and its implications on the constitution of the deaf person. Reflections on linguistic issues within the school space have shown a bilingual philosophical trend for the deaf. This philosophy considers Libras, as a language of instruction, and the teaching of the Portuguese language, as a second language, in the written mode. The studies reviewed in this article reveal that we must reflect on the process of inclusion of deaf students at schools and that this cannot be anchored simply in the gathering of these students with the hearing students in regular classrooms, as we witness today in public schools (FELIPE, 2006). It is necessary that there is a change throughout the school structure for the validation of the linguistic rights of the deaf, since the didactic-pedagogical relations consider the peculiarities of the different modalities of both languages, as well as the language, culture, identity of the deaf, and interaction as fundamental factors in their cognitive and social development.
\end{abstract}

Key-words: Education of the deaf, Interaction, Learning process

\title{
Resumen
}

En este artículo se discuten algunas cuestiones teóricas sobre el bilingüismo (BAKER, 2004; GROSJEAN, 1982; MYERS-SCOTTON, 2006), tomando como eje central la educación para sordos en Brasil (FELIPE, 2006; FERNANDES, 1990; LACERDA y LODI, 2009; QUADROS, 2012) y sus consecuencias en la construcción del sujeto sordo. Las reflexiones sobre cuestiones lingüísticas dentro del espacio escolar han demostrado una tendencia bilingüe para la educación de los sordos. Ese método considera la lengua brasileña de señas (libras) como la lengua de instrucción y la enseñanza de la lengua portuguesa, como segunda lengua, en la modalidad escrita. Las investigaciones revelan que es necesaria una reflexión sobre el proceso de inclusión de los alumnos sordos en la escuela y que ésta no puede estar fundamentada simplemente en la inserción de esos alumnos con los alumnos oyentes en las aulas regulares, conforme presenciamos hoy en las escuelas públicas (FELIPE, 2006). Es necesario que haya una transformación relacionada a la ratificación de los derechos lingüísticos de los sordos en toda la estructura escolar, pues las relaciones didácticopedagógicas consideran las peculiaridades de las diferentes modalidades de ambas lenguas, así como la relación lengua, cultura, identidad del sordo y la interacción como factores fundamentales en su desarrollo escolar y social.

Palabras-clave: Educación de sordos, Interacción, Proceso de aprendizaje. 


\section{Referências}

ALBRES, N. A. Português: eu quero ler e escrever. São Paulo: Instituto Santa Terezinha, 2010.

ANATER, G. I. P. As marcações linguísticas não-manuais na aquisição da língua de sinais brasileira (LSB): um estudo de caso longitudinal. 2009. 160 f. Dissertação (Mestrado em Linguística) - Centro de Comunicação e Expressão, Universidade Federal de Santa Catarina, Florianópolis, 2009.

ARROTÉIA, J. O papel da marcação não-manual nas sentenças negativas em Língua de Sinais Brasileira (LSB). 2005. 113 f. Dissertação (Mestrado em Linguística) - Instituto dos Estudos da Linguagem, Universidade Estadual de Campinas, Campinas, 2005.

BAKER, C. Deaf people, bilingualism and bilingual education. In: Foundations of bilingual education and bilingualism. 4. ed. Great Britain: Multilingual Matters, 2004. p. 370-380.

Foundations of bilingual education and bilingualism. 5. ed. New York: Multilingual Matters, 2011.

BARROS, M. E. ELiS: sistema brasileiro de escrita das línguas de sinais. Porto Alegre: Penso, 2015.

BRASIL. Lei $\mathbf{n}^{\mathbf{0}}$ 9.394, de 20 de dezembro de 1996. Estabelece as diretrizes e bases da educação nacional. Diário Oficial da União, Brasília, DF, seção 1, 23/12/1996, p. 27833 (Publicação Original).

Lei $\mathbf{n}^{\mathbf{0}}$ 10.436, de 24 de abril de 2002. Dispõe sobre a Língua Brasileira de Sinais Libras e dá outras providências. Diário Oficial da União, Brasília, DF, seção 1, 25/4/2002, p. 23 (Publicação Original).

Decreto $\mathrm{n}^{\circ}$ 5.626, de 22 de dezembro de 2005. Regulamenta a Lei $\mathrm{n}^{\circ} 10.436$, de 24 de abril de 2002, que dispõe sobre a Língua Brasileira de Sinais - Libras, e o art. 18 da Lei ${ }^{\circ}$ 10.098, de 19 de dezembro de 2000. Diário Oficial da União, Brasília, DF, seção 1, 23/12/2005, p. 28 (Publicação Original).

BUTLER, Y. G.; HAKUTA, K. Bilingualism and second language acquisition. In: BHATIA, T. K.; RITCHIE, W. C. (Ed.). The Handbook of bilingualism. Oxford: BlackwellPublishingLtd, 2006. p. 114-144.

CAPOVILLA, F. C. Filosofias educacionais em relação ao surdo: do oralismo à comunicação total ao bilingüismo. Revista Brasileira de Educação Especial, v. 6, n. 1, p. 99-116, 2000.

CHAVEIRO, N. Qualidade de vida das pessoas surdas que se comunicam pela língua de sinais: construção da versão em Libras dos instrumentos WHOQOL-BREF e WHOQOL-DIS. 
2011. 252 f. Tese (Doutorado em Ciências da Saúde) - Faculdade de Medicina, Universidade Federal de Goiás, Goiânia, 2011. Disponível em: <http://repositorio.bc.ufg.br/tede/handle/ tde/1527>. Acesso em: 14 jul. 2017.

CICCONE, M. M. C. Comunicação total: introdução, estratégia e a pessoa surda. Rio de Janeiro: Editora Cultura Médica, 1990.

CUMMINS, J. Bilingual children's mother tongue: why is it important for education?. Sprogforum, Tonronto-CA, v. 7, n. 1, p. 15-23, 2009. Disponível em: <http://www.iteachile arn.com/cummins/mother.htm>. Acesso em: 15 ago. 2016.

DOMAGALA-ZYSK, E. Deaf and hard of hearing primary school pupil's motivation to learn English as a foreign language. In: BYRA, S.; CHODKOWSKA, E. (Ed.). Socio-pedagogical contexts of social marginalization. Lublin: UMCS, 2013. p. 159-176.

DONATO, R. Collective scaffolding in second language learning. In: LANTOLF, J. P.; APPEL, G. (Ed.). Vygotskian approaches to second language learning. Norwood-NJ: Ablex Publishing Company, 1994. p. 39-62.

EMMOREY, K.; BORINSTEIN, H.; THOMPSON, R.; GOLLAN, T. Bimodal bilingualism. Bilingualism, Cambrige-England, v. 11, n. 1, p. 43-61, 2008. Disponível em: <https://www. ncbi.nlm.nih.gov/pmc/articles/PMC2600850/>. Acesso em: 9 nov. 2017.

FELIPE, T. Escola inclusiva e os direitos linguísticos dos surdos. Revista Espaço, v. 7, p. 4146, 1997.

Política públicas para inserção da Libras na educação de surdos. Revista Informativo Científico Espaço - INES, Rio de Janeiro, n. 25/26, p. 33-47, jan./dez. 2006.

FELIPE, T. A; MONTEIRO, M. S. Libras em contexto: curso básico. 7. ed. Rio de Janeiro: WallPrint, 2008.

FERNANDES, E. Problemas linguísticos e cognitivos do surdo. Rio de Janeiro: Agir, 1990.

FERREIRA, L. Por uma gramática de língua de sinais. 2. ed. Rio de Janeiro: Tempo Brasileiro, 2010.

FERREIRA-BRITO, L. Uma abordagem fonológica dos sinais da LSB. Revista Informativo Científico Espaço - INES, Rio de Janeiro, v. 1, n. 1, p. 20-43, 1990.

Integração social \& educação de surdos. Rio de Janeiro: Babel, 1993.

FIGUEIREDO, F. J. Q. de. (Org.). A aprendizagem colaborativa de línguas. Goiânia: Editora da UFG, 2006a.

A aprendizagem colaborativa de línguas: algumas considerações conceituais e terminológicas. In: (Org.). A aprendizagem colaborativa de línguas. Goiânia: Editora da UFG, 2006b. p. 11-45. 
Aprendendo com os erros: uma perspectiva comunicativa de ensino de línguas. 3. ed. rev. ampl. Goiânia: Editora da UFG, 2015.

FIGUEIREDO, F. J. Q.; OLIVEIRA-SILVA, C. M. Uma análise da eficácia das estratégias de ensino utilizadas por uma professora ministrando aulas de inglês instrumental para alunos surdos em uma sala de aula inclusiva na universidade. In: FIGUEIREDO, F. J. Q.; SIMÕES, D. M. P. (Org.). Linguística Aplicada, prática de ensino e aprendizagem de línguas. Campinas, SP: Pontes Editores, 2016. p. 235-282.

FIGUEIREDO, F. J. Q.; SILVA, S. V. A colaboração no ensino-aprendizagem de línguas em contextos tecnológicos: Uma análise das interações entre aprendizes brasileiros e alemães. In: FIGUEIREDO, F. J. Q.; SIMOES, D. M. P. (Org.). Metodologias em/de linguística aplicada para ensino e aprendizagem de línguas. Campinas, SP: Pontes Editores, 2014. p. 73-117.

FIGUEREDO, C. J. O uso de estratégias de comunicação em sala de aula de língua inglesa: a interação em foco. 2001. 164 f. Dissertação (Mestrado em Letras e Linguística) Faculdade de Letras, Universidade Federal de Goiás, Goiânia, 2001.

FOX, M. Talking hands: what sign language reveals about the mind. New York: Simon \& Schuster Paperbacks, 2007.

GÓES, M. C. R. Linguagem, surdez e educação. 2. ed. Campinas-SP: Editora Autores Associados, 1999.

GOLDFELD, M. A criança surda: linguagem e cognição numa perspectiva sóciointeracionista. São Paulo: Plexus, 1997. p. 24-40.

GROSJEAN, F. Life with two languages: an introduction to bilingualism. CambridgeLondon: Harvard University Press, 1982.

KLIMA, E. S.; BELLUGI, U. The signs of language. 3. ed. Cambrige-London: Harvard University Press, 1980.

LACERDA, C. B. F. Um pouco da história das diferentes abordagens na educação dos surdos, 1998. Disponível em:

<http://150.164.100.248/dialogosdeinclusao/data1/arquivos/LACERDA

_Historia_Abordagens_Educacionais.pdf >. Acesso em: 12 set. 2016.

LACERDA, C. B. F.; LODI, A. C. B. A inclusão escolar bilíngue de alunos surdos: princípios, breve histórico e perspectivas. In: LODI, A. C. B.; LACERDA, C. B. F. (Org.). Uma escola duas línguas: letramento em língua portuguesa e língua de sinais nas etapas iniciais de escolarização. Porto Alegre: Mediação, 2009. p. 11-32.

O intérprete educacional de língua de sinais no Ensino Fundamental: refletindo sobre limites e possibilidades. In: LODI, A. C. B. et al. (Org.). Letramento e minorias. 7. ed. Porto Alegre: Mediação, 2014. p. 120-137. 
LANE, H. A máscara da benevolência: a comunidade surda amordaçada. Lisboa: Horizontes Pedagógicos, 1995.

LEMOS, M. T. G. A língua que me falta: uma análise dos estudos em aquisição de linguagem. Campinas, SP: Mercado de Letras, 2002.

MACHADO, P. C. Integração/Inclusão na escola regular: um olhar do egresso surdo. In: QUADROS, R. M. (Org.). Estudos Surdos I. Petrópolis: Arara Azul, 2006. p. 38-75.

MARCHESI, A.; MARTÍN, E. Comunicação, linguagem e pensamento das crianças surdas. In: COLL et al. (Org.). Desenvolvimento psicológico e educação: necessidades educativas especiais e aprendizagem escolar. Porto Alegre: Artes Médicas, 1995. p. 198-231.

MEIER, R. P. Why different, why the same? Explaining effects and non-effects of modality upon linguistic structure in sign and speech. In: MEIER, R. P.; CORMIER K.; QUINTOPOZOS, D. (Org.). Modality and structure in signed and spoken languages. Cambridge: Cambridge University Press, 2002. p. 1-25.

MELLO, H. A. B. Madrinha ou madrasta? O papel da L1 na aquisição da L2. Signótica, v. 16, n. 2, p. 213-242, jul./dez. 2004.

Práticas discursivas em uma sala de aula de ESL: uma análise microetnográfica. In: REES, K. D.; MELLO, B. A. H.; FERREIRA, D. F. C. M. (Org.). Múltiplas Vozes. Goiânia: Editora da UFG, 2008. p. 106-129.

. Educação bilíngue: uma breve discussão. Horizontes de Linguística Aplicada, v. 9, n. 1, p. 118-140, 2010.

MYERS-SCOTTON, C. Who is a bilingual? What factors promote bilingualism? In: Multiple Voices: An introduction to Bilingualism. Malden-MA: Blackwell, 2006. p. 35-66.

NYIKOS, M.; HASHIMOTO, R. Constructivist theory applied to collaborative learning in teacher education: In search of ZPD. The Modern Language Journal, v. 81, n. 4, p. 506$517,1997$.

OLIVEIRA, M. K. Vygotsky: aprendizado e desenvolvimento: um processo sócio-histórico. São Paulo: Scipione, 1998.

OLIVEIRA, Q. M.; FIGUEIREDO, F. J. Q. de. Aprendizagem de libras e português em contexto de tandem: um estudo realizado com uma aluna surda e uma ouvinte da Universidade Federal de Tocantins. Caderno Seminal Digital, v. 28, n. 28, p. 1-24, 2017.

OLIVEIRA-SILVA, C. M. A aprendizagem colaborativa de inglês instrumental por alunos surdos: um estudo com alunos do curso de Letras: Libras da UFG. 2017. 262 f. Tese (Doutorado em Letras e Linguística) - Faculdade de Letras, Universidade Federal de Goiás, Goiânia, 2017. 
PEREIRA, M. C. C. (Org.). Leitura, escrita e surdez. Secretaria da Educação, CENP/CAPE. 2. ed. São Paulo: FDE, 2009.

Papel da língua de sinais na aquisição da escrita por estudantes surdos. In: LODI, A. C. B. et al. (Org.). Letramento e minorias. 7. ed. Porto Alegre: Mediação, 2014. p. 45-52.

PERLIN, G. Identidades surdas. In: SKLIAR, C. (Org.). A surdez: um olhar sobre as diferenças. Porto Alegre: Mediação, 1998. p. 51-73.

Identidades surdas. In: SKLIAR, C. (Org.). A surdez: um olhar sobre as diferenças. 7. ed. Porto Alegre: Editora Mediação, 2012. p. 51-73.

PICONI, L. B. Teaching languages to deaf students in Brazil at the intersection of discourses. Revista Brasileira de Linguística Aplicada, v. 14, n. 4, p. 881-904, 2014.

PIRES, L. C.; LOPES, R. E. V. A aquisição da flexão em português escrito por sinalizantes surdos: uma reflexão inicial sobre educação bilíngue. In: LIMA-SALLES, H. M. M. (Org.). Bilinguismo dos surdos: questões linguísticas e educacionais. Goiânia: Cânone Editorial, 2007. p. 17-47.

QUADROS, R. M. Educação de surdos: a aquisição da linguagem. Porto Alegre: Artmed, 1997.

. O 'BI' em bilinguismo na educação de surdos. In: FERNANDES, E.; SILVA, A. C., et al. (Org.). Surdez e bilinguismo. 6. ed. Porto Alegre: Mediação, 2012. p. 27-37.

QUADROS, R. M.; FINGER, I. Teorias de aquisição da linguagem. Florianópolis: UFSC, 2008.

QUADROS, R. M.; KARNOPP, L. B. Língua de sinais brasileira: estudos linguísticos. Porto Alegre: Artmed, 2004.

RABELO, A. S. Português sinalizado: Comunicação Total. v. 1. Goiânia: Editora UCG, 1992a. p. 11-37. 09-12.

Português sinalizado: Comunicação Total. v. 2. Goiânia: Editora UCG, 1992b. p.

RIGONATO, L. G. N. A correção com os pares em um contexto de ensino-aprendizagem de Português como Língua Estrangeira: um estudo com alunos intercambistas na UFG. 2017. 164 f. Dissertação (Mestrado em Letras e Linguística) - Faculdade de Letras, Universidade Federal de Goiás, Goiânia, 2017.

SABOTA, B. Trançando os fios da leitura em língua inglesa: por uma resolução colaborativa de exercícios de compreensão textual. In: FIGUEIREDO, F. J. Q. de. (Org.). A aprendizagem colaborativa de línguas. Goiânia: Editora da UFG, 2006. p. 81-109. 
SACKS, O. W. Vendo vozes: uma viagem ao mundo dos surdos. São Paulo: Companhia das Letras, 1998.

SANDLER, W.; LILLO-MARTIN, D. Sign language and linguistic universals. Cambridge: Cambridge University Press, 2006.

SANTOS, H. T. S. A construção de identidades na educação de surdos. Curitiba: Editora Prismas, 2016.

SKLIAR, C. A surdez: um olhar sobre as diferenças. Porto Alegre: Editora Mediação, 2015.

SOUZA, R. G. Que palavra que te falta? Lingüística e educação: considerações epistemológicas a partir da surdez. São Paulo: Martins Fontes, 1998.

SOUZA, S. A.; ALMEIDA, S. H. S. Leitura-escrita em inglês com surdos: uma abordagem dialógica. Revista Eventos Pedagógicos, 10. ed., v. 5, n. 1 (número especial), p. 140-148, jan./maio 2014.

STROBEL, K. As imagens do outro sobre a cultura surda. 2. ed. Florianópolis, SC: Editora da UFSC, 2009. p. 31-37.

STUMPF, M. R. Prefácio. In: WANDERLEY, D. C. A leitura e escrita de sinais de forma processual e lúdica. Curitiba: Editora Prismas, 2015. p. 11-12.

STUMPF, M. R.; QUADROS, R. M. Tradução e interpretação da língua brasileira de sinais: formação e pesquisa. Cadernos de Tradução, v. 2, n. 26, p. 165-205, 2010.

TSUI, A. B. M. Introducing classroom interaction. London: Penguin, 1995.

VALli, C.; LUCAS, C.; MULROONEY, K. J.; VILLANUEVA, M. Linguistics of American sign language: an introduction. 5. ed. Washington-DC: Gallaudet University Press, 2011.

VYGOTSKY, L. S. A formação social da mente: o desenvolvimento dos processos psicológicos superiores. São Paulo: Martins Pontes, 1998.

Pensamento e linguagem. 4. ed. São Paulo: Martins Fontes, 2008.

WANDERLEY, D. C. A leitura e escrita de sinais de forma processual e lúdica. Curitiba: Editora Prismas, 2015.

WOOD, D.; BRUNER, J. S.; ROSS, G. The role of tutoring in problem solving. Journal of Child Psychology and Psychiatry, v. 7, p. 89-100, 1976. 


\section{Notas}

${ }^{1}$ Conforme afirma Strobel (2009), o termo "povo surdo" refere-se às pessoas surdas que se identificam com a língua de sinais e com a luta pelo reconhecimento do surdo como pertencente a uma comunidade linguística e cultural minoritária. Por sua vez, o termo "comunidade surda" refere-se aos surdos e ouvintes que participam dessa luta.

${ }^{2}$ Optamos por grafar a palavra "libras", com letras minúsculas, por entendermos que é uma língua natural e as línguas naturais são grafadas com letras minúsculas em português, da mesma forma que o fez Oliveira-Silva (2017).

${ }^{3}$ Federação Mundial do Surdo.

${ }^{4}$ Como exemplo dessas tecnologias, temos os aparelhos de amplificação sonora, o desenvolvimento de terapias de fala etc. (CICCONE, 1990; RABELO, 1992a, 1992b).

5 “Leitura labial” refere-se ao ato de ler os movimentos dos lábios durante a fala oral (QUADROS, 1997).

${ }^{6}$ Entende-se por "datilologia" o ato de soletrar manualmente a representação das letras das línguas orais por uma sequência de configurações de mão que as representam nas línguas de sinais (QUADROS; KARNOPP, 2004).

7 "Português sinalizado" é o uso dos léxicos da língua de sinais brasileira de acordo com a estrutura da língua portuguesa, privilegiando a sintaxe linear da língua oral e desconsiderando a sintaxe vísuo-espacial das línguas de sinais (QUADROS, 1997).

8 O que é denominado "palavra" ou "item lexical" nas línguas orais é denominado "sinal” nas línguas de sinais. O sinal surge da combinação dos parâmetros: configuração das mãos, ponto de articulação, movimento, orientação, expressão facial ou corporal (cf. FELIPE; MONTEIRO, 2008).

${ }^{9}$ Para mais informações sobre essas políticas públicas, veja Felipe (2006).

10 A FENEIS é uma entidade filantrópica com finalidade sociocultural, assistencial e educacional para a comunidade surda brasileira, localizada na cidade do Rio de Janeiro. Para mais informações sobre essa instituição, veja: < http://feneis.org.br>.

$11 \mathrm{O}$ intérprete de libras educacional é um profissional que surge nas políticas públicas de inclusão do surdo nas escolas para mediar a comunicação entre os alunos surdos e demais pessoas (LACERDA; LODI, 2009, 2014).

12 Entende-se por "cultura surda" as experiências culturais vivenciadas pelos surdos (STROBEL, 2009), tais como a literatura surda, a contação de piadas e as datas comemorativas, como o "Setembro Azul", mês em que se comemoram as conquistas linguísticas, políticas e culturais dos surdos.

13 As línguas de sinais são reconhecidas atualmente como línguas de grupos surdos bilíngues minoritários. São línguas usadas por uma comunidade surda, a qual está inserida em um contexto majoritariamente oral auditivo (BUTLER; HAKUTA, 2006).

14 Há diferentes concepções de sujeito bilíngue. Para este estudo, entendemos que bilíngues são pessoas que conhecem e usam duas línguas (BUTTER; HAKUTA, 2006).

15 Os conceitos de input e output referem-se ao processamento linguístico de compreensão e de produção de uma língua, trazidos pela abordagem inatista. São ativados quando o sujeito é exposto a línguas (FIGUEIREDO, 2015; QUADROS; FINGER, 2008).

16 Nossa tradução de: use their two languages with different people, in different contexts and for different purposes. 
17 "Língua adicional" é o termo aplicado para designar todas as línguas estudadas por uma pessoa, exceto a primeira (OLIVEIRA-SILVA, 2017).

18 Wood, Bruner e Ross (1976) definiram a assistência que se dá no auxílio da execução de uma tarefa como scaffolding. De acordo com os autores, scaffolding, traduzido por "andaime" em português, é um processo que possibilita ao aprendiz solucionar um problema, executar uma tarefa, ou alcançar um objetivo, o qual não seria possível sem a ajuda de outra pessoa (FIGUEIREDO, 2006b). 